\title{
CHAPTER 12: WORKING WITH PEOPLE WITH INTELLECTUAL DISABILITIES
}

\section{Personal Story}

\author{
James's story \\ My name is James and I am 24 years old. I live with Simon, Colin and \\ Stanley in a house. It is ok, but the others are noisy and shout \\ sometimes. Care staff help us do things like shopping and cleaning the \\ house. I go to the day centre and do things on the computer. I like \\ walking and playing computer games. Mum comes to see me on a \\ Saturday. I have a brother called Harry. Sometimes I get angry and \\ shout. Mum tells me off.
}

\section{Summary}

This chapter looks at why, and how, a clinical psychologist might work with a person with intellectual disabilities. It provides a definition of what intellectual disability is and how it is assessed. The epidemiology and aetiology of intellectual disabilities will also be described. The chapter will explain that clinical psychologists do not see people because they have intellectual disabilities, but as a consequence of the additional challenges faced by people in this group. Having an intellectual disability may bring additional physical and life challenges that most people would find difficult to manage. However, having intellectual disabilities also means that your intellectual capacity is more limited meaning that dealing with these issues can be even more difficult, leaving you vulnerable to experiencing a greater risk of psychological and behavioural problems. Clinical psychologists are well equipped to help individuals with intellectual disabilities in this situation and may work directly with them, their carers or with wider organizational care and support services. The chapter will describe the types of interventions used and their evidence base, and provide a case example of how such a problem may be assessed, formulated and an intervention developed. Historically, people with intellectual disabilities have been a group that have been excluded and stigmatized and it has been difficult for them collectively to challenge this position. Today, the picture is more positive with people with intellectual disabilities having more opportunity to voice their concerns and exert their right to access appropriate services, however as will be explored at the end of the chapter there remains a fine balance between the expression of individual choice and protection by others, which remains one of the most critical issues facing working in this area today. 


\section{Jan Burns chapter - working with people with Intellectual Disabilities}

\section{Learning Outcomes}

When you have completed this chapter you should be able to:

\begin{tabular}{|l|l|}
\hline 1 & $\begin{array}{l}\text { Know what intellectual disabilities are, what might be some of the causes and other } \\
\text { issues which co-occur. }\end{array}$ \\
\hline 2 & $\begin{array}{l}\text { Have an understanding of the sorts of challenges people with intellectual disabilities } \\
\text { may face both dealing with their own impairments, but also dealing with the views of } \\
\text { society. }\end{array}$ \\
\hline 3 & $\begin{array}{l}\text { Be able to position the experience of people with intellectual disabilities within wider } \\
\text { psychological theories. }\end{array}$ \\
\hline 4 & $\begin{array}{l}\text { Have an understanding of the key psychological approaches in this area, how other } \\
\text { treatment approaches might be adapted, and the evidence base for this. }\end{array}$ \\
\hline 5 & $\begin{array}{l}\text { Through a case example understand how assessment, formulation, intervention and } \\
\text { evaluation are used. }\end{array}$ \\
\hline 6 & $\begin{array}{l}\text { Be able to understand how different approaches, at different levels from the } \\
\text { individual to the support network, might be integrated to be effective and } \\
\text { sustainable. }\end{array}$ \\
\hline
\end{tabular}

\section{Introduction}

This chapter will introduce you to the work of the clinical psychologist working with people with learning disabilities, their carers and the organisations which support them. Having intellectual disabilities is not a reason alone for being involved with clinical psychology, but it is often the consequences which accompany these disabilities which require intervention. It is important to think of it in terms of intellectual disabilities, not just an intellectual disability as individuals will have different profiles in terms of their cognitive limitations, and whilst they have strengths in one area they will have weaknesses in other areas, and as a consequence of this unique constellation of impairments each person will face different challenges.

Within this chapter you will learn more about the definition of intellectual disabilities, what causes them, and other issues which frequently co-occur. You will also learn about how the clinical psychologist may work with the person with intellectual disabilities, their carers and the organisations which aim to support them. 


\section{Diagnosis}

Intellectual Disability (sometimes termed Learning Disability in the UK) is defined in DSM-5 as an impairment of mental abilities which results in a reduced ability to manage everyday life, called adaptive functioning. Three domains or areas of adaptive functioning are described:

1. The conceptual domain which includes skills in language, reading, writing, memory, maths, and reasoning;

2. The social domain refers to empathy, social judgment, interpersonal communication skills, the ability to make and retain friendships, and similar capacities;

3. The practical domain includes being able to look after yourself, such as personal care, money management, getting around and managing your time.

The intellectual disability must have occurred during the person's developmental period of growth and diagnosis is based on the severity of the impact on adaptive functioning. The disorder is considered chronic and is often co-morbid with other disorders such as Autism. Having an intellectual disability is not in itself a psychological problem, but the challenges and stigma attached to the disorder places significant stress on the individual placing them more at risk to psychological problems.

\section{What are the types of psychological difficulties that can occur in people with intellectual disabilities}

People with intellectual disabilities can suffer the same sorts of psychological problems as anybody else in life. However, the prevalence rates of many psychological problems tend to be higher for people with intellectual disabilities (Taylor and Knapp, 2013). This vulnerability results from both the additive (i.e. the accumulation of additional problems) element of intellectual disabilities and the very nature of the disorder which means that the individual's capacity to manage their situation intellectually is compromised. The additional challenges faced by people with intellectual disabilities fall into three main areas:

1. Intellectual disability linked disorders. Generally people with intellectual disabilities are more likely to have additional physical problems, such as sensory deficits, mobility and respiratory problems. Some types of intellectual disabilities are a consequence of genetic syndromes which also have accompanying additional disabilities, both physical (e.g. Downs syndrome and hearing loss) and behavioural (e.g. Prader-Willi syndrome and over-eating). Some conditions such as Autism, Epilepsy and Cerebral Palsy also have a 
greater likelihood of co-occurrence with intellectual disabilities. The more severe the intellectual disabilities the higher the likelihood of a range of associated disorders. Having additional physical impairments leads to increased vulnerability by impacting on learning opportunities and can lead to increased isolation and reduction of stimulation, causing additional psychological stress.

2. Common psychological problems. People with intellectual disabilities can suffer from problems such as anxiety and depression, the same as everyone else; however they are vulnerable to experiencing this more frequently because of the tough demands of living in our society with intellectual disabilities. Hence, people with intellectual disabilities are more vulnerable to all the accepted setting conditions for common psychological problems such as low income, poor housing, unemployment, poor health and social isolation.

3. Stigma and prejudice. Having intellectual disabilities within our society is still stigmatising i.e. de-valued, which means that people behave in prejudicial and exclusionary ways. This is especially difficult for people with intellectual disabilities as they have fewer psychological resources to manage negative attitudes and are even less able than other disenfranchised groups to fight for their rights. Being in such a socially devalued position brings additional psychological pressures to an already vulnerable group.

Hence, clinical psychologists do not tend to see people because they have an intellectual disability, but more usually as a consequence of them having an intellectual disability which has placed them in a more psychologically vulnerable position. It is useful to consider the problems faced by the individual within an ecological framework, which then may require the psychologist to work at a number of different levels to minimize the impact of the impairments caused by the disability. The framework has the individual within the centre surrounded by support or organizational structures, offering a variety of ways in which the psychologist may intervene (see Fig.1).

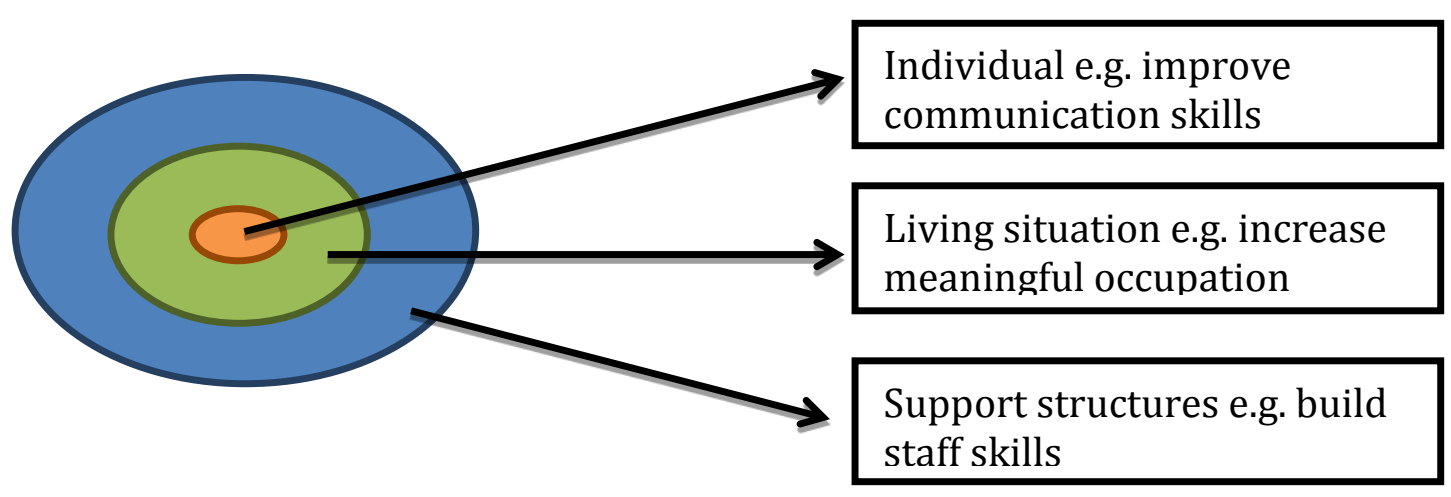

Figure 1: Points of intervention within an ecological framework surrounding an individual with intellectual disabilities. 


\section{Jan Burns chapter - working with people with Intellectual Disabilities}

\section{Epidemiology}

Getting good statistics on the epidemiology of intellectual disabilities in the UK is problematic for a number of reasons, firstly in terms of identification, secondly in terms of different data collection methods across the UK and thirdly through changing epidemiological profiles related to changing definitions, medical interventions, health behavior and demographic profiles. However, a good source of information is the Improving Health and Lives: Intellectual Disabilities Intellectual Disabilities Observatory (http://www.improvinghealthandlives.org.uk/) which produces regular updates on the current and changing epidemiology.

It is estimated that in 2012 in England 1,144,000 people had learning disabilities, of which 236,000 were children and 908,000 adults (aged 18+). Of the adults 199,000 $(22 \%)$ are known to GPs as people with intellectual disabilities and 404,000 (44\%) were receiving Disability Living Allowance (Emerson et al 2013). Hence, it is clear from these statistics that a large number of people are living with either no need of being identified as having intellectual disabilities, or in contrast are not receiving required services.

Of those identified as having intellectual disabilities the average age of mortality is 24 years $(30 \%)$ younger than the rest of the population. However, there are important fluctuations in epidemiology to note resulting from changing medical practices, such that there is a lower population over age 49 , and an increasing population of males under 20. This is because there now tend to be more males born with intellectual disabilities, particularly with severe intellectual disabilities, where improvements have been made in survival rates.

\section{Aetiology}

A good place to start to understand the aetiology of intellectual disabilities is from the World Health Organisation's (WHO) International Classification of Functioning, Disability and Health (2002) as it provides a useful biopsychosocial model (see Fig. 2).

Fig. 2: International Classification of Functioning, Disability and Health (WHO, 2002)

Health condition

(disorder or disease)

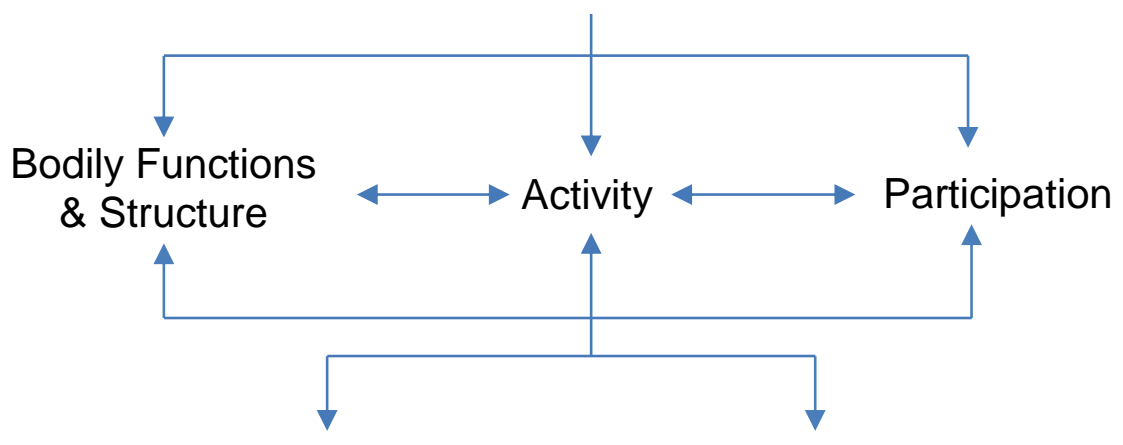




\begin{tabular}{|c|c|}
\hline $\begin{array}{c}\text { Environmental } \\
\text { Factors }\end{array}$ & $\begin{array}{c}\text { Personal } \\
\text { Factors }\end{array}$ \\
\hline
\end{tabular}

Contextual factors

If we start at the top of the model we can consider the biological contributions to the aetiology of learning disabilities. These include congenital causes, such as genetic (e.g. Downs syndrome), acquired, both prenatal (e.g. maternal drug abuse), postnatal (e.g. birth trauma), social (e.g. malnutrition) and environmental (e.g. toxins). All of these events may lead to structural and functional negative impacts on the neurological system. However, even with careful assessment it must be recognised that the biological aetiology remains unknown in over $50 \%$ people with intellectual disabilities (see Smith and Tyler, 2009 for further reading on causal factors).

Moving to the middle layer of the diagram we can consider how these biological factors might impact upon body function and structure. Taking the example of an infant with Downs syndrome they are likely to have cognitive deficits, physical differences such as hypotonia (low muscle tone) and sensory problems such as hearing loss, in addition to other issues. Considering their ability to be active, and like any baby, to explore curiously and play with their environment, without appropriate adjustment their experience will be more limited. Not being able to hear well, and not having the expected cognitive reactions and ability to learn, may then impact on the interpersonal attachments a person makes and which may further impede their ability to participate in the activities and relationships around them. Participation is important as it brings richer learning opportunities and reinforces, encourages and motivates future engagement.

Looking at the bottom of the diagram we can see that we must also consider the environmental and personal factors which will impact on the outcomes for the individual with intellectual disabilities. Environmentally, just considering the young person with Downs Syndrome where their disability is visually recognisable, the reaction of others to this identity will be very important for the self-esteem and inclusion of the person. Also the existing knowledge about the condition will have a significant impact upon expectations and importantly what adjustments might need, or not need, to be made to help the person overcome their disabilities. Personal factors include the personality of the individual, their own resilience and coping styles, but also their gender and age as these will present different challenges during different developmental stages.

The WHO model is helpful as it moves the focus away from the disability to the more fluid concept of functioning, which is dependent upon the above interrelating set of factors. Such a model suggests a wider range of possibilities in terms of intervention. It also raises the issue that contrary to taking a medical, organic approach to intellectual disabilities, these disabilities could also be conceptualized in terms of a social construction, i.e. something which only exists in this time and place as a 


\section{Jan Burns chapter - working with people with Intellectual Disabilities}

consequence of how we structure our society (Rapley, 2004). Clearly, we would not define intellectual disabilities in the same way if we did not have IQ tests with cut-off points, based on purely statistical concepts, or ways of life which demanded high levels of literacy. However, likewise some individuals do have such severe impairments that no matter what their social context was, they would find it impossible to cope. Holding both positions in mind is helpful in ensuring a holistic approach.

\section{Theory and Evidence for Psychological Intervention}

Psychological interventions with people with intellectual disabilities have a long history, but mostly within applied behavioural analysis, and less so within the application of 'talking therapies'. This was partly due to emphasis being given to the co-modification of the behavior of people with intellectual disabilities to 'fit in' with institutional environments, and historical beliefs that their thoughts and feelings were not accessible. These days a more respectful, integrated approach is taken, particularly in terms of managing challenging behavior and also the full range of therapeutic modalities are considered as applicable, with appropriate adjustment. The following sections describe a current behavioural approach to managing behaviours which may be seen as challenging, and the a short review of the types of 'talking therapies' which have been found to be helpful.

\section{Positive Behaviour Support}

There are times when a person's behavior is seen as 'challenging', and challenging behaviour has been defined as;

"Culturally abnormal behaviour(s) of such an intensity, frequency or duration that the physical safety of the person or others is likely to be placed in serious jeopardy, or behaviour which is likely to seriously limit use of, or result in the person being denied access to, ordinary community facilities." (Emerson, 2001).

Rather than see this as an individual pathology it is recognized that it is a socially constructed, dynamic concept and where the individual's quality of life and risk management are paramount. The most accepted approach to manage challenging behavior is Positive Behaviour Support (PBS; Dunlap, Sailor, Horner and Sugai, 2009; Baker and Allen, 2012) which is based upon Applied Behavior Analysis (ABA) principles, but set within a clear framework of values. As opposed to pure ABA it is also multi-element, non-linear (i.e. recognizing that multiple antecedents and consequences may act upon a behavior simultaneously) and designed to result in a range of outcomes, which are sustainable and achieved through positive means. PBS has a number of components:

1. Comprehensive functional analysis to try and understand what purpose the behavior serves for the individual. Then on the basis of this assessment a number of strategies; 


\section{Jan Burns chapter - working with people with Intellectual Disabilities}

2. Ecological strategies - trying to ensure that the environment meets the need of the person as much as possible, e.g. if the individual can't read make sure signage or communication tools use symbols or pictures which they do recognise;

3. Positive programming - teach the person skills to help them control their environment, e.g. using headphones;

4. Focussed support strategies - designed to manage the context and reduce the need for reactive strategies, e.g. avoid noisy environment at stressful times

5. Reactive strategies - designed to get control of the situation once the behavior has occurred, and reduce escalation e.g. help the individual move to a quieter place.

PBS is the most commonly recommended approach with challenging behavior and there is good evidence for its effectiveness. For example in a recent review LaVigna and Willis (2012) concluded that applying the ethical criteria of 'least restrictive intervention' it is effective, open to all involved in managing such behavior and cost effective. It is recognized that the efficacy of the approach is reliant upon those who need to deliver it which are usually the staff who work directly with the individual on a day-today basis, so McDonald and McGill (2013) conducted a review of the effectiveness of teaching staff this approach. They concluded that there was evidence for a reduction in challenging behaviour, and increases in staff positive attributions and knowledge; however they recognized the evidence was limited and no improvement in quality of life has been demonstrated.

\section{Talking Therapies}

More recently talking therapies have been shown to be effective with people with intellectual disabilities as long as adaptations are made to ensure that the individual can engage with the model. Willner (2005) reviewed the existing literature on the effectiveness of cognitive-behaviour therapy (CBT), cognitive therapy and psychodynamic approaches, and concluded that evidence exists for all three models to be effective with people with mild intellectual disabilities and sometimes effective with people with more severe intellectual disabilities. However, the review recognised that research was very limited and particularly lacking randomized controlled designs, and information on how such models were adapted. Since then a small number of RCTs have been published with positive results, particularly around using CBT for anger management (e.g. Willner, et al 2013), and also other studies on helping people with intellectual disabilities to use CBT (Bruce et al, 2010) and on how simple CBT elements can be adapted for staff for use with their clients (Dodd, et al 2013).

Whilst Willner (2005) concluded there was some limited evidence for the use of psychodynamic psychotherapy with this client group, further evidence for its effectiveness has been slower to follow and the suitability of this model has been more contested. However, more recently evidence has been growing for its potential effectiveness, but with a clear acknowledgement that the practices and procedures used within the application of this modality with this client group requires further description (Jackson and Beail, 2013). 


\section{Jan Burns chapter - working with people with Intellectual Disabilities}

As the use of 'talking therapies' have become more accepted the breadth of the therapeutic models being used has widened, following the growing evidence base within mainstream work. Hence, a recent book published on 'Psychological Therapies for Adults with Intellectual Disabilities (Taylor, et al, 2013) also includes mindfulness and acceptance based approaches.

\section{Case Example}

Pat is a 46 year old lady with Downs Syndrome. She has been referred to the community learning disability team as she has started to get up and wander at night, disturbing other residents of the group home and the sleep-over night staff. She sometimes becomes quite agitated when asked to return to bed, and generally seems down and weepy. When asked what is wrong she seems unable to identify anything.

Dementia and Downs Syndrome
Downs Syndrome (DS) is the most common genetic cause of learning
disabilities. Due to better medical intervention in early life people with DS are
now living longer and the higher prevalence rate of dementia for people with
Downs Syndrome at an earlier expected age has been recognized. Research
suggests comorbidity is between $10 \%-25 \%$ in the 40 - to 49 -year-old group,
$20 \%-50 \%$ in the 50 - to 59 -year-old group and between $30 \%-75 \%$ in those aged
60 years or older. There seems to be no relationship between level of learning
disability and risk or dementia, but pre-existing cognitive function is related to
rate of decline. Behavioural change tends to indicate onset more frequently
than functional memory decline. The most common form of dementia
comorbid with DS is of the Alzheimers type. The link is related to the shared
function of the protein Amyloid. Amyloid forms the neural plaques found in
Alzheimers disease and the gene coding for this protein is located on
chromosome 21 . The majority of people who have DS have the 'trisomy 21 '
form which means they have an extra copy of this chromosome, disrupting
normal Amyloid production. However, not all people with DS develop dementia
in later life and the reason for this is unclear.

\section{Assessment}

Pat has been asked by her key worker if she would like to talk to someone about the problems she has been experiencing. She readily agreed and an appointment was made for her to see the clinical psychologist on the specialist intellectual disabilities team. The clinical psychologist explained that she would like to talk to Pat to see if she can help her, and that it would also help for her to talk to the staff so she can get a complete picture. Pat consented to this initial assessment. Pat told the psychologist that she was aware she was getting up in the night, that it made her upset and anxious, and that the staff were cross with her, but she did not know why she did it. On talking to staff it was clear that they were concerned, felt that Pat's behaviour had deteriorated generally and wondered if she was started to show dementia. The night time disrupted routines were having a bad effect on the other residents and one member of staff thought Pat was doing it to get attention as sometimes she was given a hot chocolate and chat before returning to bed. When 


\section{Jan Burns chapter - working with people with Intellectual Disabilities}

asked if anything had changed recently staff mentioned that Pat's auntie who she was close to had died about six months ago and they had had some work done to the house which meant that the upstairs bathroom had been out of commission for a couple of weeks, so residents had had to use the downstairs bathroom, but it was all fine now.

It was agreed, given Pat's age and the existence of no previous dementia screening, that she should undergo some psychometric tests, and meanwhile more information would be gathered about Pat's nocturnal behavior and generally how she was feeling. With Pat's consent $A B C$ charts were completed by the night staff over a three week period, these logged Antecedents (anything staff noticed before Pat got up in the night), the Behaviour (what she did and what staff did) and Consequences, (what happened after). The Clinical Psychologist also agreed with Pat to meet her for six sessions to discuss how she was feeling and to try and understand what led to the nocturnal wandering.

\section{Formulation}

It is important in a complex case like this that a very careful and thorough assessment is made which is based on an initial formulation. As the work progresses it is likely that additional information will come to light which enriches and confirms and rejects ideas present in the initial formulation. The following formulation is an initial formulation which leads to an action plan to gather more information which will lead to the consolidation of the most appropriate formulation of the problem and continuing action plan.

It seemed clear that something had changed to give rise to these changes in behavior which had not been reported before. There may be a number of reasons for this change. Given Pat's age and Downs Syndrome she has a 25-50\% higher chance than those without Downs Syndrome of developing dementia which can lead to confusion, anxiety and behavioural change. Downs Syndrome and dementia were potential 'pre-disposing' factors (making Pat more at risk of the current problems), to be investigated further. Pat had also recently experienced the death of someone close to her, and with no other close family this loss was significant. The grieving process is individual but it is likely that Pat was still mourning this loss. At a practical level there had been some work done on the house which may have disrupted her usual routines, and on top of these other factors she was finding it hard to reestablish a routine. These could be termed 'precipitating' factors as bereavement is a known cause of psychological distress and having routines disrupted can be particularly upsetting for people with intellectual disabilities, and Pat's behavior changed quite soon after these events.

Pat was also starting to feel generally quite anxious as she felt staff may be feeling cross with her, which again may disrupt her sleep. This could be seen as a 'perpetuating' factor because it maintains the behavior, possibly beyond the influence of the initial precipitating events. As Pat becomes more aware of the staff's negative feelings, she becomes more anxious, which in turn disrupts her sleep, and the events continue in a cyclical fashion. Any combination of these factors could have been contributing to this behaviour so it was important to find out more information before intervening. 


\section{Action plan}

\section{Comprehensive Assessment}

$>$ A dementia screening assessment was carried out using the Neuropsychological Assessment of Dementia in Adults with Intellectual Disabilities (NAintellectual disabilities). (Crayton et al., 1998). Also to establish a behavioural baseline Pat's adaptive functioning was assessed using the Adaptive Behaviour Assessment System-II (ABAS-II) (Harrison \& Oakland, 2003)

> The Glasgow Anxiety Scale for people with an Intellectual Disability (GASintellectual disabilities) was used to assess level of anxiety (Mindham, \& Espie, 2003). Pat scored 13 which just hit the cut-off of $13-15$ to be seen as clinically significant.

$>$ The clinical psychologist met with Pat to explore with her in greater depth the anxiety she was experiencing. They also talked in detail about Pat's bedtime routines. She had felt disrupted by the work on the house, now sometimes forgetting to get a drink of water and going to the toilet before bed. She was also anxious about turning the lights on when she got up in case of waking the night staff, who slept with the door open, but then ended up going in the wrong room or having to turn the light on which made her feel cross with herself and embarrassed.

$>$ Ten ABC charts were completed over a three week time period, showing that Pat did not get up every night, and there was no particular pattern in terms of which days, but that it did tend to happen around 2.00am. She then stopped up for variable amounts of time depending on what approach staff took. Some tried to sending her to bed, which tended to make her agitated, others sat up with her for a while and sometimes made a drink. There was only one occasion when she got up more than once.

\section{Re-Formulation}

According to the screening Pat did not have dementia, but given this predisposing factor, having a baseline screening follows national guidance. The precipitating factor of bereavement did seem significant, and hence it was appropriate to intervene to resolve some issue and reduce distress about this event. The assessment also illuminated another perpetuating factor - Pat was keeping the light off to reduce disturbance but by doing so was causing more disturbance and adding to her anxiety levels. The assessment also confirmed that the disruption to routines through building work had perpetuated the situation; hence it was clear that a more standard routine needed to be re-established and agreed with Pat and the staff. 


\section{Intervention}

$>$ A meeting was held with the staff team to discuss the results of the assessment and action plan. After consulting Pat a procedure was agreed about what should happen if Pat got up, which consisted of two main elements, checking if she wanted to go to the toilet, and going with her to get a drink of water (not a hot drink), then going with her back to her room and settling her in bed. Pat was also to be reassured by staff that they were not cross about her waking. Time was also spent carefully explaining this to Pat's key worker so she could ensure that all the night staff who could not make the meeting were well informed.

> Pat formed a good rapport with the clinical psychologist and they spent time discussing her deceased auntie, what grief feels like and how things start to feel better. They used a downloadable booklet about grief specifically for people with intellectual disabilities, developed by the NHS North Tyne's Liverpool Care Pathway group (NHS North East, 2012).

$>$ Pat agreed that she still felt very sad about her Auntie's death, but felt she could not say this to the staff as she thought they might think 'she was going on' and 'should be over it now', because they never mentioned her Auntie now. Pat agreed that the clinical psychologist could let the rest of the staff team know this and Pat's key worker suggested that together they could make a photo album featuring her Auntie.

$>$ Night lights had been installed in the corridor to the bathroom, which made Pat feel more confident.

\section{Outcome}

$\checkmark$ The dementia screening did not show any dementia, but it was agreed that Pat should be assessed on an annual basis.

$\checkmark$ Pat previously scored 13 on the GAS-intellectual disabilities, but when tested 8 weeks later this had reduced to 8 , indicating a return to normal levels of anxiety.

$\checkmark$ The staff team stuck to the agreed procedure and after another 3 week period of monitoring with $\mathrm{ABC}$ charts there had only been one incident.

$\checkmark$ Staff reported feeling more confident and relieved. They were especially pleased that they raised the topic of dementia and that they had followed the guidelines (Royal College of Psychiatry \& Division of Clinical Psychology, 2009), in that they were right to be concerned given Pat's age, Downs Syndrome and change in behavior (reactive monitoring) and that Pat was now registered for annual reviews (prospective monitoring). Staff had found the use of the $A B C$ charts helpful and reported that they would use them again. They also realized that their anxiety had been noticed by Pat and misinterpreted by her as them being angry with her, hence how important it was to check with Pat what she was thinking. 


\section{Jan Burns chapter - working with people with Intellectual Disabilities}

\section{Team working/Indirect work}

It was very important to work with the staff team in this case as these were the people who knew Pat the best and spent long periods of time with her. There was clearly a communication difficulty in that the staff were genuinely concerned, but Pat misinterpreted this which made her feel more anxious, exacerbating the situation. It is not uncommon for seemingly simple and predictable feelings and interactional dynamics to become confused, so asking both the staff team and the client what they might feel and how they might behave in the others situation is a good way of testing out and challenging these beliefs.

Setting systems in place that are sustainable are very important as the clinical psychologist is only likely to be involved for a short period of time and the bulk of the work will be carried out and continued by the staff team. Hence, their active engagement is vital. Also with each clinical intervention it is an opportunity to provide the staff team with more understanding, tools and strategies to help them in their work and provide an improving service to their clients. In this case getting Pat's approval to talk to the staff team about how she was feeling was vital. It also provided an opportunity to find out how they were feeling and to be able to identify some misunderstandings. It was also important to identify with both the staff and Pat the outcomes they desired. In this situation they were shared outcomes meaning we could find strategies to work together for an agreed outcome. When objectives are not shared between the client and staff or even within the same staff team this must be identified and worked upon. It was also important to contextualize the staff's 'hunch' that they 'needed to check for dementia'. Discussing the 'Dementia and People with Learning Disabilities' guidelines with the staff made them feel confident in their decision making, and gave them a resource to draw on should they have further concerns. Likewise the ABC chart was a resource they found helpful and could see themselves using again, which may increase their own capacity to problem solve similar situations.

In this case the work of the clinical psychologist was quite contained to Pat and the direct team who worked with her. However, it is not uncommon to involve other members of the multi-disciplinary team such as the speech and language therapist for communication issues, or the team nurse to help manage physical issues. Also wider issues may be identified where staff training by the psychologist can be of benefit, or there may be problems with how the team is working where again the clinical psychologist could help.

\section{Critical Issues}

As the rights of people with intellectual disabilities have been given more attention, the centrality of their voice and choices has also been given more authority. However, with this comes difficult and complex choice making around a vulnerable person's right to be protected and their right to act in the way they choose. Many of the critical issues within the field of psychology and intellectual disabilities currently centre on this dilemma. One particularly contested area of work is around the 


\section{Jan Burns chapter - working with people with Intellectual Disabilities}

expression of sexuality, where issues of right to choose, consent, parenthood, protection of self and others, and public prejudice have all had to be addressed.

Historically the sexuality of people with intellectual disabilities has been either denied or tightly controlled. Today it is acknowledged that all people with intellectual disabilities have the same rights to a sex life as everybody else, whilst acknowledging that this must be within consensual understanding (McCarthy and Thompson, 2010). This may be difficult in two particular circumstances, when the individual(s) concerned lack understanding to give consent and/or there is such a power imbalance that coercion may be involved. With heterosexual sex comes the possibility of pregnancy so not only must individuals have the capacity to understand the sexual act, but they must also understand that this may lead to pregnancy, and to make the choice to accept this possibility or be able to take precautions. For clinical psychologists these dilemmas have brought not only many invitations to become involved in trying to establish 'capacity for consent', but also to provide assistance in assessment and intervention to help people live sexually fulfilled lives.

Concerning sexual behavior this may involve straightforward sex education, to helping staff work through complex issues such as a young man with intellectual disabilities asking a member of staff to show them how to put on a condom. Like the mainstream world some people with intellectual disabilities wish to engage in less normative sexual practices and for staff concerned about the expression of sexuality anyway, managing a client who wants to cross-dress, or has a shoe fetish poses additional challenges. Commonly in such complex, ethically challenging cases clinical psychologists are invited in to assist in helping staff both establish capacity for consent and support staff through the array of complex decisions and actions which may lie before them.

At a more serious edge of transgression lies sexual offending and there has been a rapid growth in forensic psychology with this client group. With rights comes responsibilities and if people with intellectual disabilities are found to have capacity and make wrong decisions then they have become increasingly involved in the judicial system. Likewise it may not be recognized that offenders have intellectual disabilities and we have seen recognition of a large prison population with unmet needs in this area.

\section{Box: Conclusion to the Personal Story (150 words)}

I met Amy who is a Psychologist. She helped me and told me what to do if I feel angry. We had a house meeting and Amy came too. We agreed some rules about making noise and Amy drew pictures and put them on the wall. If Colin is noisy I point to the picture and he shuts up.

In the morning I go with Jim now and deliver newspapers. It was hard at first but I like it now. People say 'hello James' and I give them their paper. 


\author{
Key concepts and terms (50 words) \\ Learning disabilities \\ Intellectual disabilities \\ Cognitive functioning \\ Autism \\ Adaptive behavior \\ Developmental period \\ Challenging behavior \\ Downs syndrome \\ Positive behavioural support \\ Applied Behaviour Analysis \\ Capacity \\ Stigma \\ Working with staff \\ Sexuality \\ Dementia
}

\title{
Sample essay titles (50 words)
}

1. Is 'learning disability' a social construction?

2. What is 'challenging behaviour' and how is it best managed?

3. How has the acceptance of the sexuality of people with intellectual disabilities changed over the years?

4. Do we understand the link between Downs Syndrome and dementia?

\section{References (700 words)}

Baker, P. and Allen, D. (2012). Use of positive behaviour support to tackle challenging behaviour. Learning Disability Practice, 15(1), 18-20.

British Psychological Society, Royal College of Psychiatrists, \& Royal College of Speech and Language Therapists, (2007), Challenging Behaviour: A Unified Approach, Leicester: DCP, British Psychological Society.

Brown, M., Duff, H., Karatzias, T., \& Horsburgh, D. (2011). A review of the literature relating to psychological interventions and people with intellectual disabilities: Issues for research, policy, education and clinical practice. Journal of Intellectual Disabilities, 15(1), 31-45.

Bruce, M., Collins, S., Langdon, P., Powlitch, S., \& Reynolds, S. (2010). Does training improve understanding of core concepts in cognitive behaviour therapy by people with intellectual disabilities? A randomized experiment. British Journal of Clinical Psychology,49(1), 1-13.

Crayton, L., Oliver, O., Holland, A., Bradbury, J. \& Hall, S. (1998). The Neuropsychological assessment of age-related cognitive deficits in adults with Down's syndrome. Journal of Applied Research in Intellectual Disabilities, 11, 255-272. 


\section{Jan Burns chapter - working with people with Intellectual Disabilities}

Dodd, K., Austin, K., Baxter, L., Jennison, J., Kenny, M., Lippold, T., ... \& Wilcox, E. (2013). Effectiveness of brief training in cognitive behaviour therapy techniques for staff working with people with intellectual disabilities. Advances in Mental Health and Intellectual Disabilities, 7(5), 8-8.

Dunlap, G., Sailor, W., Horner, R. and Sugai, G. (2009). Overview and History of Positive Behavior Support. In: W. Sailor, G. Dunlap, G. Sugai and R. Horner (Eds). Handbook of Positive Behavior Support. New York: Springer.

Emerson, 1995, cited in Emerson, E (2001, 2nd edition): Challenging Behaviour: Analysis and intervention in people with learning disabilities. Cambridge University Press.

Emerson, E., Hatton, C., Robertson, J. Baines, S., Christie, A. \& Glover, G. (2013). People with Intellectual Disabilities Intellectual Disabilities in England in 2012. Improving Health and Lives: Intellectual Disabilities Intellectual Disabilities Observatory.

Harrison, P.L. \& Oakland, T. (2003). Adaptive Behaviour Assessment System (ABAS-II) (2nd ed.) . New York: The Psychological Corporation.

La Vigna, G. \& Willis, T. (2012). The efficacy of positive behavioural support with the most challenging behaviour: The evidence and its implications. Journal of Intellectual and Developmental Disability, 37, 185-195

MacDonald, A. \& McGill, P. (2013). Outcomes of Staff Training in Positive Behaviour Support: A Systematic Review, Journal of Developmental and Physical Disabilities, 25,(1), 17-33.

McCarthy, M. and Thompson, D. (Eds) (2010). Sexuality and Learning Disabilities: A Handbook. Brighton: Pavilion.

Mindham, J., \& Espie, C. A. (2003). Glasgow Anxiety Scale for people with an Intellectual Disability (GAS-intellectual disabilities): development and psychometric properties of a new measure for use with people with mild intellectual disability. Journal of Intellectual Disability Research, 47(1), 22-30.

NHS North of Tyne (2012). Grieving - easy read - supplementary booklet. NHS North East. http://www.cnne.org.uk/end-of-life-care---the-clinical-network/careatendoflife. Accessed $16^{\text {th }}$ January 2014.

Rapley, M. (2004). The Social Construction of Intellectual Disability, Cambridge: Cambridge University Press.

Royal College of Psychiatrists \& Division of Clinical Psychology: Faculty for Learning Disabilities, (2009). Dementia and People with Intellectual Disabilities Intellectual Disabilities Guidance on the assessment, diagnosis, treatment and support of people with intellectual disabilities who develop dementia, Leicester: British Psychological Society.

Smith, D. and Tyler, N. (2009). Introduction to Special Education: Making a Difference. Seventh Edition. New Jersey: Pearson

Taylor, J. and Knapp, M. (2013). Mental Health and Emotional Problems in People with Intellectual Disabilities. In J. Taylor, W. Lindsay, R. Hastings, and C. Hatton (Eds). Psychological Therapies for Adults with Intellectual Disabilities, Wiley: New York

Taylor, J., Lindsay, W., Hastings, R. \& Hatton, C. (Eds) (2013). Psychological Therapies for Adults with Intellectual Disabilities, Wiley: New York

Willner, P. (2005), The effectiveness of psychotherapeutic interventions for people with learning disabilities: a critical overview. Journal of Intellectual Disability Research, 49, 73-85. 


\section{Jan Burns chapter - working with people with Intellectual Disabilities}

Willner, P., Rose, J., Jahoda, A., Kroese, B. S., Felce, D., Cohen, D., ...\& Hood, K. (2013). Groupbased cognitive-behavioural anger management for people with mild to moderate intellectual disabilities: cluster randomised controlled trial. The British Journal of Psychiatry. On line doi:10.1192/bjp.bp.112.124529

World Health Organisation. (2002). Towards a Common Language for Functioning, Disability and Health: ICF - The International Classification of Functioning, Disability and Health. Geneva: WHO.

\section{WEB RESOURCES}

intellectual disabilities

1. Social care Institute for excellence - a source of a wide range of resources to help professionals working with people with learning disabilities http://www.scie.org.uk/topic/people/peoplewithlearningdisabilities

2. Improving Health and Lives Intellectual Disabilities Intellectual Disabilities Observatory - lots of accessible information about the health of people with learning disabilities http://www.improvinghealthandlives.org.uk/

3. NHS North East - Two downloadable booklets about end of life and bereavement for people with intellectual disabilities to work through http://www.cnne.org.uk/end-of-life-care---the-clinical-network/careatendoflife

4. Faculty for Intellectual Disabilities Intellectual Disabilities of the British Psychological Society - useful guidance documents http://dcp-ld.bps.org.uk/dcp-Id/publications/

5. Family Planning Association - A list of resources to help manage an individual with intellectual disabilities sexuality http://www.fpa.org.uk/shop/12/product-list

6. British Institute of Intellectual Disabilities Intellectual Disabilities - a range of useful resources http://www.bild.org.uk/information/useful-resources/

7. Mencap - information and campaigning charity http://www.mencap.org.uk/ 